\title{
CIUDAD HISTÓRICA HABITADA "VIDA CONTEMPORÁNEA/HOGAR HISTÓRICO" MANIFIESTO DESDE AREQUIPA HACIA LATINOAMÉRICA ${ }^{[*]}$
}

\author{
INHABITED HISTORICAL CITY \\ "CONTEMPORARY LIVING/HISTORIC HOME" \\ MANIFEST FROM AREQUIPA TO LATIN AMERICA \\ MÓNICA LOAYZAVELA ${ }^{(\star x)}$ \\ (D) https://orcid.org/0000-0001-8417-3133 \\ moniloave@gmail.com \\ DOT Lab: Laboratorio de producción ciudadana (Perú) \\ Fecha de recepción: 19 de octubre de 2019 \\ Fecha de aprobación: 5 de junio de 2020
}

\section{RESUMEN}

¿Si más allá de rehabilitar la vivienda de nuestro centro histórico, para generar usos de paso, contemplativos y bonitos, nos proponemos entre todos gestionar su renovación integral? ¿Podríamos amplificar nuestra identidad colectiva y recuperar las relaciones que nos otorgan derechos como sujetos patrimoniales? Se admiten propuestas.

Nuestra Ciudad no fue así desde el comienzo, como uno imagina. En su momento fue pueblo niño. Había otra ciudad debajo de esta, y otra y otra más de sillares amarillos de sol y callecitas de tierra. Y por una de esas callecitas ahí, crecieron nuestros padres y abuelos, muy de cuerpo presente vivieron. Y ese fue el momento y la luz de ellos.

Mas ahora, para nosotros es diferente, mantenemos una desvelada memoria del pasado que por lo general deconstruye nuestra ciudad histórica, reconfigurando escenarios y personas, en ausencia de vivienda, negándoles una verdadera conexión con el tiempo y diversidad en su unión histórica. Y ese, precisamente, es el motivo y la búsqueda de nuestro manifiesto.

\section{PALABRAS CLAVE}

Centro Histórico; habitante; vivienda

\begin{abstract}
What if beyond rehabilitate housing of our historical center, to generate passing uses, contemplative and beautiful, we propose among all manage your integral renewal? Can we amplify our collective identity and retrieve the relationships that give us rights as 'patrimonial subjects'? Proposals are admitted.

Our City was not like this from the beginning, as you can imagine. At the time it was a boy village. There was another city below this, and another and another more of ashlars yellow sun and unpaved streets. And by one of those little streets, our parents and grandparents grew up, much of present body they lived. And that was the moment and the light of them. But now for us is different, we maintain a disclosed a memory of the past which generally deconstructs our historic city, reconfiguring scenarios and people, in the absence of housing, denying them a true connection with the time and diversity in its historical union. And that is precisely the reason and the search of our manifest.
\end{abstract}

\section{KEYWORDS}

Historic center; inhabitant; housing.

\footnotetext{
(*) El artículo forma parte de una investigación multidisciplinaria sobre vivienda en el centro histórico. Surge tras la publicación del libro La Cabezona Tambo de la Memoria, ganador de la Convocatoria 2017 de Sistematización de experiencia y publicaciones de Puntos de Cultura del Ministerio de Cultura del Perú.

(**) Arquitecta por la Facultad de Arquitectura y Urbanismo de la Universidad Nacional de San Agustín (Arequipa). Funda DOT lab y La Nube, laboratorios de producción ciudadana e investigación urbana respectivamente. Autora del libro La Cabezona Tambo de la Memoria. El patrimonio como memoria social: Representación del pasado e identidad cultural en la ciudad histórica habitada de Arequipa, ganador de la Convocatoria 2017 de Sistematización de experiencia y publicaciones del programa de Puntos de Cultura del Ministerio de Cultura del Perú.
} 


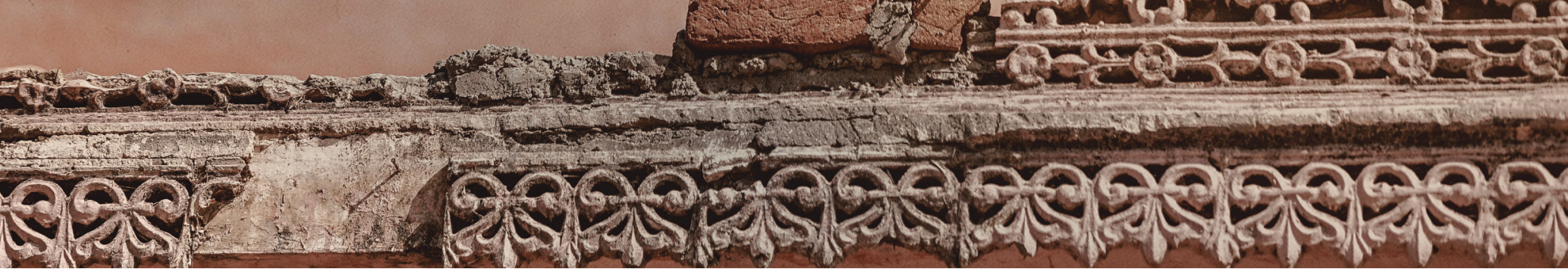

Figura 1. Las casas tienen paredes de viento y techo de nubes. Centro histórico de Arequipa. Archivo fotográfico de la autora, 2019.
"Lo que no había podido decirle la casa antigua a su amiga, para no entristecerla, era que ellas estaban ligadas no solo por los momentos que habían pasado juntas en los últimos tiempos solas, sino también por los destinos de todos los que habían sido parte de la vida de ambas y que, después del entierro de la anciana señora, ella (...) la seguiría al mundo del más allá, donde las casas tienen paredes de viento y techo de nubes" (Sala, 2006).

\section{Dispersos. Supone el olvido.}

Y todo olvido es, en definitiva, un error de percepción o de memoria, es indicio de que, en cierto modo, nos deshacemos en una multiplicidad dispersada. Por el contrario -en cuanto sigue siendo nada más que una especie de opuesto complementarionuestra verdadera presencia es una multiplicidad orientada, es la diversidad que se haya en función de la complejidad unificada interiormente y puede existir en nosotros "seres maravillosamente ondeantes y diversos" (Lacroix,1965:37).

A primer vistazo la última expresión no advierte más que un aspecto personal, sin embargo, un análisis más hondo imagina descubrir en ella ciertas notas sociales. Pero, tanto ese análisis más hondo como el primer vistazo deben ser objeto de revisión, sólo que, como de lo complejo a lo complicado no hay nada más que un paso —y la simplicidad es para nosotros un fin casi inaccesible- buscaremos en nuestra opinión unificar ambas ideas, contradictorias en teoría, pero inseparablemente entreveradas en una sola y misma realidad: la sociedad creada, nuestra vida en Ciudad' (ver Figura 1).

1. Como define E. Lalo (2002) en el libro La isla silente, La Ciudad con mayúscula, constituye un lugar de apropiaciones y trasformaciones de la memoria colectiva perteneciente a un grupo de sujetos reales que la habitan, conservan y transmiten. 
$180^{\circ}$
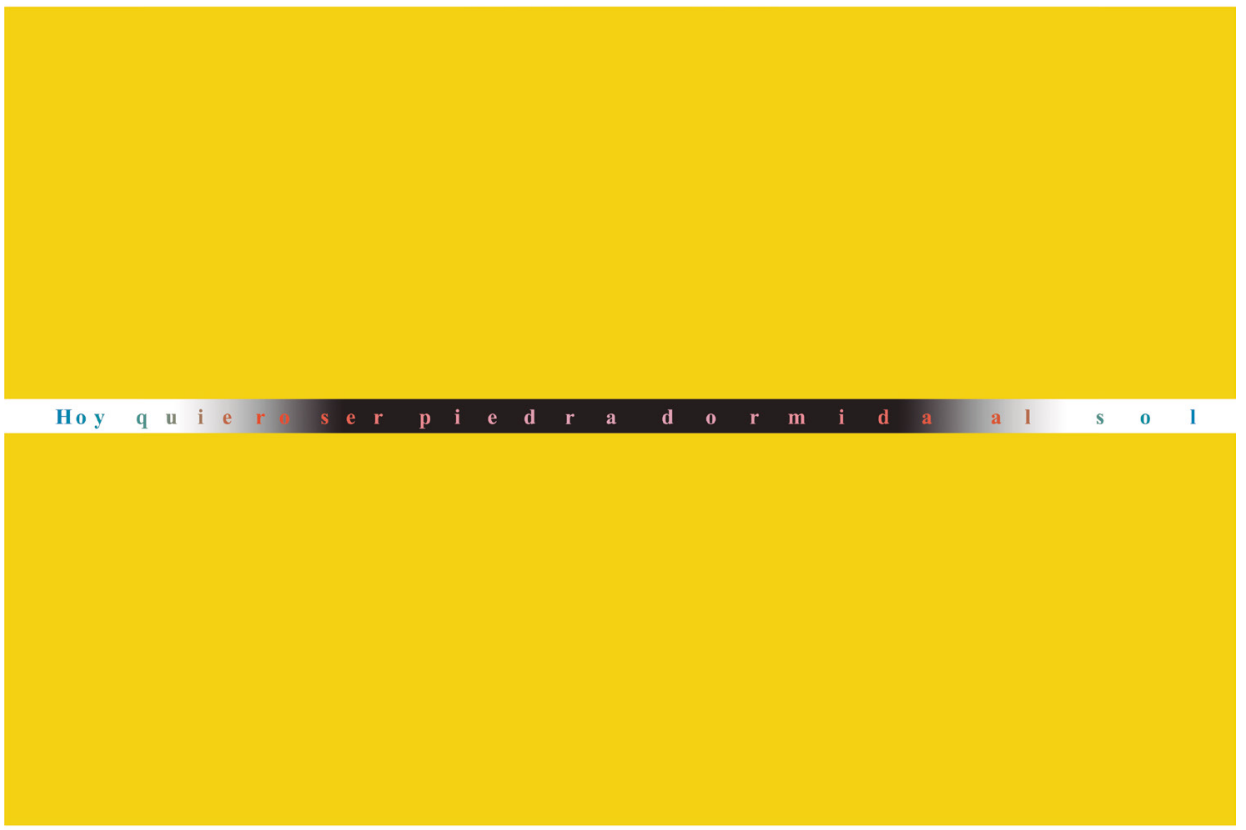

Las piedras sueñan ser pedazos de luna Sueña el agua con su barco

Ser entonces mutación de brizna a hoja

frágil, perfilada, diminuta

Sueño en línea quebrada

Ser horizonte como único objetivo

Sueño

Sobre suelo blanco

Bajo cielo blanco.

La otra orilla - recuerda, somos del pantano-

Figura 2. Hoja la sueño. $\mathbf{1 8 0}^{\circ}$. Poema visual. Elaboración propia, 2019.

Ahora que, incorporamos las variables 'vida'y 'Ciudad', y al no hallar dificultad en insertarlas al contexto de nuestra cotidianeidad, caemos en cuenta que producen en nosotros un nexo profundo que nos permite develar aquel elemento siempre presente, determinante y que supone de nuestra parte espontaneidad previa, nos referimos a la "vivienda" en todas sus formas.

Esa 'espontaneidad previa' admitida y que nos proporciona el ímpetu vital, está fundada en nuestras memorias y en la "comunicación contagiosa de las imaginaciones vigorosas"2 (Lacroix,1964:33) de nuestros padres y abuelos, que enlazan la vivienda de

2. Nicolas Malebranche, filósofo y teólogo francés, al analizar lo que llamaba "comunicación contagiosa de las imaginaciones vigorosas", vio en ello el vínculo social más común y natural en las personas pertenecientes a una misma familia. 
devenir Vol. 7, N¹4, JULIO - DICIEMBRE 2020, PP. 53-70 - EstudIOS I ISSN 2312-7562 | E-ISSN 2616-4949

UNIVERSIDAD NACIONAL DE INGGENIERÍA, LIMA

doi: https://doi.org/10.21754/devenir.v7i14.758

antaño en amistad razonable con el presente; relación que, como la amistad, supone a la vez unión en el tiempo y diversidad en su unión histórica. Y de eso, precisamente de la vida y vivienda constituida en el centro histórico, intentaremos a continuación desplegar algunos reflejos de nuestra razón hasta llegar al entendimiento primero personal y luego — si se puede-colectivo.

Nos parece necesario que a partir de este momento el pasado, presente y futuro (recuerdos, propósito actual e imaginaciones) deberán estar, como un continuo, activos en el interior de nuestra mente. Ha llegado entonces la hora de reconciliarlos, de volver a unir el significado, humanamente esencial, y multiplicarlo entre nosotros; si no es así, las opiniones que se desprendan carecerán de profundidad temporal y de capacidad de asociación que otorguen a nuestra presencia validez en toda la extensión de la realidad que nos circunda, siempre y sobre todo bajo la perspectiva singular de nuestras experiencias vividas. (ver Figura 2).

\title{
Hoja al sueño
}

\author{
"no se desea lo que no se conoce o lo que precisa \\ tiempos socialmente 'no productivos' \\ (ya saben, pensar, aburrirse, soñar, poetizar...). \\ Con vivir ya basta". \\ Remedios Zafra \\ (refiere aquí a su ensayo más reciente Ojos y capital, \\ (h)adas y un cuarto propio conectado)
}

Ocurre que tanto las ciudades como sus ciudadanos se aburren algunas veces, y este aburrimiento puede dar origen a las mayores desventuras individuales y sociales en nuestro mundo. ¿O no? Veamos.

El aburrimiento es, en efecto, una llamada que no recibe respuesta alguna, una especie de vértigo en presencia del vacío interior; se trata de una experiencia difícil de expresar y sucede como prueba de que, sin duda, no ocupamos el lugar (físico o mental) que nos corresponde.

El mundo contemporáneo ha descubierto también en el aburrimiento un poder insospechado hasta hoy: basta, si puede expresarse así, turbarnos un poco, para que una vez hecho esto, corramos el riesgo de alejarnos uno del otro sin que nada pueda detenerlo; pues dicha diferenciación se limita indefinidamente a sí misma en una especie de círculo vicioso: reemplazando la elección libre y espontánea por la repetición, la reflexión por el contagio tendencioso y la voluntad por el desánimo, llegando hasta el extremo de considerar estas acciones como únicas respuestas ante nuestra realidad.

Tales son estas fuerzas de alienación, que siendo más exactos debamos considerarlas, en función a su constante aparición, como el símbolo actual de la condición humana, que no puede realizarse con plenitud sino por mediación de no sé qué hipnosis social, que libera o avasalla indiscriminadamente, y que como alucinados del mismo contagio nos condiciona a andar todos juntos, pero sin saber a dónde.

Esta misma experiencia de negación que trae consigo el aburrimiento, se nos presenta a la par favorable, gracias a un dedicado y consciente ejercicio introspectivo, pues contempla una significación personal necesaria — de fe y confianza- que en un principio llena de limitaciones y errores, permite conquistar con más plenitud un clima fundamentalmente positivo de emociones que se propagan en acciones dirigidas a uno mismo; $y$ de vez en cuando después de traspasar las apariencias de calma y claridad simulada, se desarrolla en nosotros un momento esencial de precepción, apeteciendo alcanzarnos en algún recoveco íntimo y recurrir al pasado que se acumula en el presente, donde nuestro aún creciente cuerpo de la experiencia encuentra un 'hogar' en la mente. Allí, 
precisamente es cuando caemos dentro nosotros mismos, enfatizamos la apropiación del espaciotiempo ${ }^{3}$, reconociéndolo en nuestra memoria, cuyo eco hemos oído siempre, porque está integrado en nuestro 'yo' y que en ese mismo instante admite su existencia en una forma conocida: la "casa" del pasado, nuestro lugar seguro desde la infancia, aquel modelo interior continuo y permanente que estaríamos dispuestos a reproducir en el presente, claro está, según nuestra propia y particular experiencia.

Dicho de otro modo, llenos de ingenuidad, gracia y en plena conciencia de nuestra parvedad existencial, es como aprendemos a moderar la relativa indulgencia histórica humana, que se va simplificando poco a poco en un recuerdo hasta asegurarse en nuestra conciencia al hacerse 'signo'; y que no representa 'el evento' cuántico literal de viajar hacia atrás, sino simplemente es que empezamos a ser conscientes de lo que existe en el presente, y de todo el conjunto de hechos y actuaciones que han viajado hacia este momento. De ahí su valor emocional único.

Mas, tal como es, las comprobaciones de estas elucubraciones, sean íntimas o colectivas, no llegan a unificarse todas en el 'signo' y la expresión exacta de nuestros tiempos. Nosotros los ciudadanos, después de todo, hemos estado acomodándonos en este mundo durante miles de años, y es obvio que el alcance completo de nuestra enorme experiencia psicogeográfica no puede ser contenida en el presente a no ser que miremos todo el pasado, es decir, la totalidad del esfuerzo humano dentro de él.

A menos que, fijemos nuestra atención a lo que hoy día entendemos como Centro Histórico ${ }^{4}$, que fue hace algunos años la Ciudad toda, nuestra Ciudad entera ${ }^{5}$, que gracias o razón a la progresiva imitación de otras ciudades más antiguas, se fue constituyendo en base a funciones heterogéneas. Porque una urbe, desde su definición inicial, fue el espacio de mayor diversidad y complejidad, el desprendimiento de todas las formas sucesivamente adoptadas, siendo hoy su afirmación inherente e inmanente, esa misma multiplicidad que orientó la vida en sociedad de nuestros padres, madres, abuelas y abuelos.

Ahora bien, en la medida en que hemos ido avanzando en la historia, hemos caído también en uno de los errores más grandes de nuestro tiempo: 'el olvido', hasta el punto de llevarnos a entender los centros históricos como espacios estáticos, así concebidos desde la "visión monumentalista", evidenciando el problema actual de nuestra ciudad histórica.

El Centro Histórico, es cierto, ha sido el resultado de la especialización de las funciones administrativas y comerciales de proximidad en nuestra ciudad, pero ello no significa que deba limitarse solo a dicho uso y desaparecer en él toda actividad residencial. Con el desconocimiento de la importancia de la vivienda en los centros históricos hay una pérdida de valor y de principios esenciales para su sostenibilidad.

Se hace necesario resaltar lo trascendental que tiene 'la casa' en el Centro Histórico, tanto en su nueva comprensión como en las políticas públicas que deban diseñarse, porque si ello no se hace, el pseudo-orden ${ }^{6}$ lo hará como lo ha venido haciendo, con

\footnotetext{
3. Según conceptualiza Loayza y Subia (2018) en el libro La Cabezona Tambo de la Memoria, 'espaciotiempo' es el Intervalo de tiempo y de espacio que permite constituir un punto fijo en las fases oscilantes del universo. Desde nuestro punto de vista, podemos considerarlo como un fragmento de realidad determinada.

4. Centro urbano de una ciudad, que posee carácter histórico y temporal. Se vincula a su condición de patrimonio cultural por hacer referencia a la identidad del territorio donde se emplaza.

5. Loayza y Subia (2018) en el libro La Cabezona Tambo de la Memoria, 'Ciudad entera' contempla la idea de ciudad efectivamente, pero con una intención clara de conjunto que va generando una traslación permanente de significados.

6. Sistema que se debilita al imitar al orden actual que rige el mundo. Su repetición reemplaza a la elección, su contagio a la reflexión, su desánimo a la voluntad, llegando hasta el extremo de considerarse como una verdad absoluta. Es la imagen de nuestro tiempo: nosotros no libres.
} 
devenir Vol. 7, Nº14, JULIO - DICIEMBRE 2020, PP. 53-70 - Estudios I ISSN 2312-7562 | E-ISSN 2616-4949 UNIVERSIDAD NACIONAL DE INGENIERÍA, LIMA

doi: https://doi.org/10.21754/devenir.v7i14.758

Bloom:

Onomatopeya expansiva de crecimiento primaveral.

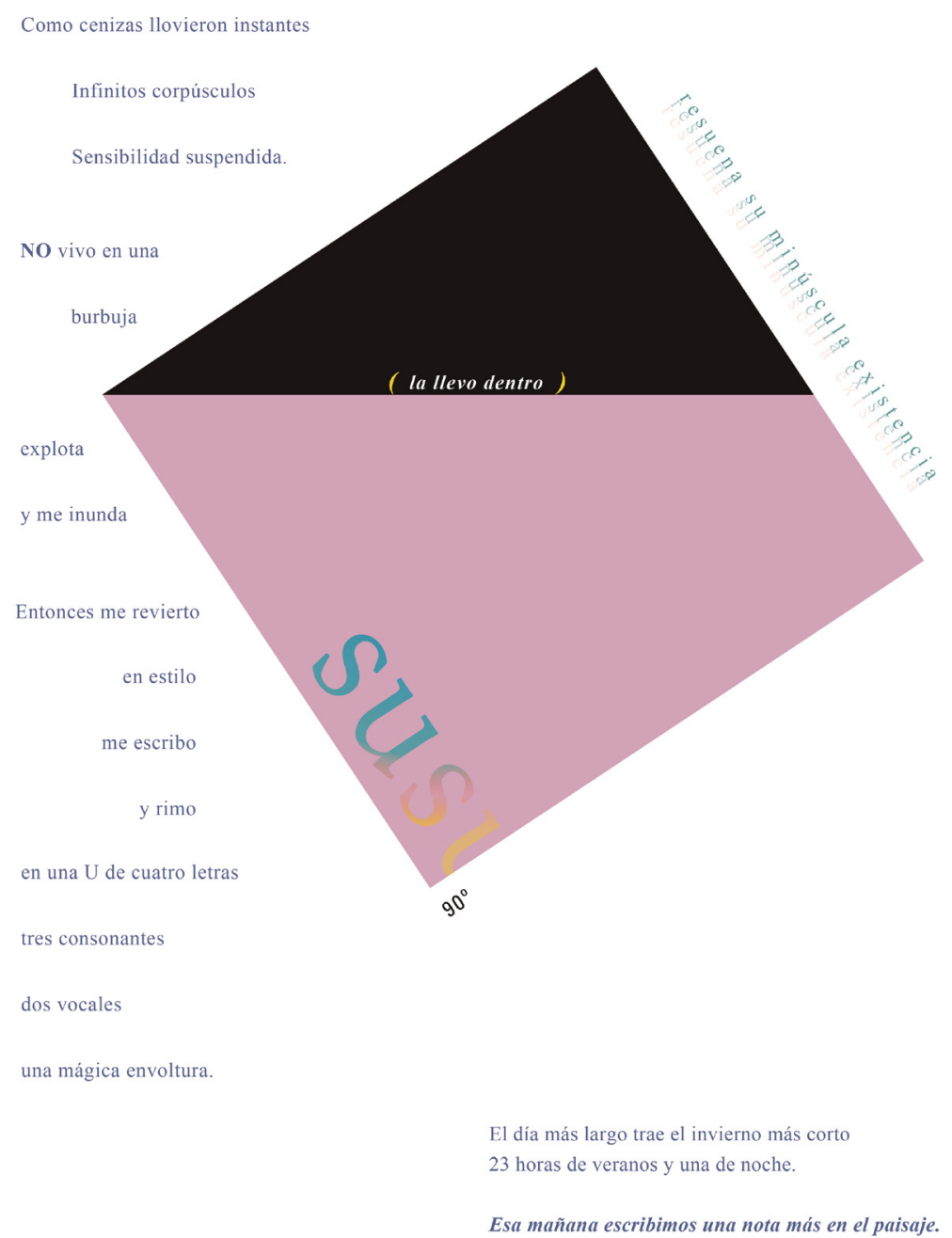

Figura 3. Susurro expansivo. $\mathbf{9 0}^{\circ}$. Poema visual. Elaboración propia, 2019.

resultados nada buenos: destrucción del patrimonio, pérdida de centralidad y expulsión de población.

Por ese lado quizás, pueda aclararse que, las estrategias de revitalización de los centros históricos deberían ser menos desde la conservación y más desde la lógica de la centralidad urbana que porta y del espacio público que construye Ciudad. Allí, están los ejemplos de las políticas conservacionistas que privilegian el urbanismo on-demand ${ }^{7}$, lo monumental, las iniciativas de las rutas turísticas que las maquillan y espectacula-

7. Nos referimos a que un servicio es 'on-demand' cuando se trata de un servicio que se ofrece bajo demanda de los usuarios. También puede decirse servicio 'a la carta'. 
rizan, aquel mito de la cultura de ocio ${ }^{8}$, que transgrede la realidad cotidiana de una Ciudad a favor de la diversión efímera de lo novedoso o la continua privatización de las calles y plazas para el comercio.

Confiamos que, más tarde que nunca, la necesidad sentida como tal, hallada no en extensión sino en comprensión, otorgará al Centro Histórico — por sus cualidades constructivas de lo público-, ya un impulso, ya un deseo, toda voluntad de construir nuestra Ciudad posible ${ }^{9}$ y retomar una pedagogía activa y social de 'la casa' en Ciudad y de los centros urbanos adaptándose a los nuevos medios, preguntando si más allá de rehabilitar centros históricos para generar sólo usos de paso, contemplativos y bonitos, podemos gestionar entre todos una rehabilitación que construya una identidad colectiva, como expresión todavía viva de la larga fase de desarrollo de nuestra sociedad, caracterizada por la presencia ${ }^{10}$ humana en un espacio acotado de múltiples funciones urbanas, de variadas actividades económicas y de una diversidad de habitantes.

Entonces 'la casa', desaparecida hasta entonces, estará por todas partes otra vez: será todo lugar, cada espaciotiempo donde se restablezca en nosotros la unidad, la unidad que la vida exige, incluye e integra a la par que nos sobrepasa y que produce tanta alegría al ciudadano-habitante de nuestra Ciudad"1 (ver Figura 3).

\section{Susurro expansivo}

(...) distingue con todo cuidado entre los animales reales (que se agitan como locos o que acaban de romper el jarrón) y los que sólo tienen su sitio en lo imaginario.

Michel Foucault

(citando a Borges)

-Tú vienes aquí y haces lo que te salga de la punta del alma, y en la medida en que lo valores y lo sientas como algo tuyo, empiezas a hacer ciudad.

Anónimo

(citando una conversación)

\section{"Como si":}

Una vez más texto y experiencia se construyeran con estructuras similares, 'como si' fuera eco el uno de la otra; pero, esta vez, ni el entendimiento, ni la razón permiten dar un solo paso hacia ellos, pues ambos son producto de un entorno cuyo carácter centrífugo y descompuesto, exige una modificación de los medios y reformulación de nuestro cuestionamiento inicial: Si el equilibrio, la armonía, la continuidad o la estabilidad alcanzada se nos presente como una farsa ¿Cómo conseguiremos producir las imágenes, o los relatos, o la Ciudad misma? Además, quizás, no solo debamos fijar nuestra atención sobre las imágenes que la ciudad produce, sino también sobre ¿Cómo se producen los significados de las imágenes de la nueva Ciudad? ¿Con qué

8. Es el conjunto de patrones culturales desarrollados en las sociedades industriales como respuesta a la gradual disminución, de la jornada laboral de las clases trabajadoras. En paralelo a todo ello surge la moderna industria del entretenimiento, que se convierte en la base para la formación de una cultura de masas.

9. Según conceptualiza Loayza (2018) en la tesis de investigación Centro de Interacción Social y Producción Cultural Colaborativa para la juventud en cerro Colorado-Arequipa, la 'Ciudad posible' asume el carácter libre de la creación y expresión cultural colaborativa, apoyado en el quehacer experimental de iniciativas ciudadanas individuales o colectivas, por lo que este territorio es lo más diverso y complejo posible

10. Según conceptualiza Loayza y Subia (2018) en el libro La Cabezona Tambo de la Memoria,'presencia' significa ser contemporáneo de uno mismo. Volverse a hallar a cada instante. Muestra la identidad de un todo confuso y virtual a un todo distinto y actual. Estar aquí.

11. Presencia humana que se reconoce como parte de una Ciudad, la construye en su quehacer cotidiano y se corresponsabiliza con su comunidad para que trascienda en tiempo y en el espacio. 
devenir Vol. 7, N¹4, JULIO - DICIEMBRE 2020, PP. 53-70 - EstudIOS I ISSN 2312-7562 | E-ISSN 2616-4949

UNIVERSIDAD NACIONAL DE INGEENIERÍA, LIMA

doi: https://doi.org/10.21754/devenir.v7i14.758

sistema de creencias se produce nuestra Ciudad contemporánea? y ¿Qué actividades calladamente propician los mejores usos ${ }^{12}$ que podemos imaginar a partir de nuestro repertorio personal de vivencias? Se admiten propuestas.

Bien, ahora intentemos calibrar soportes que sugieran sutilmente usos latentes que se manifiesten mediante nuestra imaginación e interpretación, unos usos latentes que sean espontáneos - no porque la forma los dictamine - sino que nos provoque; $y$ si, al igual que la imagen de Ciudad que ilustra la primera parte de estas reflexiones (ver "I Hoja al sueño") nuestras propuestas logran difuminarse e instalarse en la visión múltiple de Ciudad posible, entonces, y solo entonces, nos daremos por satisfechos.

Ello significa que la calibración de usos —entendida como la definición de las acciones o actuaciones específicas que calladamente el habitante propicie dentro de su entorno inmediato: 'la casa' - no será estática, sino más bien todo lo contrario, altamente dinámica; tanto que se puedan encontrar momentos históricos de reconformación, así como de transformación.

Por consiguiente, la naturalidad de estas acciones, no podrá ser basta y espontánea sin una lenta conquista que principie por aceptar nuestra propia dualidad: unidad y diversidad, parte y todo, pequeño y grande, mucho y poco, simplicidad y complejidad, cambio y constancia, orden y caos, individual y colectivo; el porqué de nuestra separación hasta el vaciado de nuestros opuestos; y porque, también, ahora estamos dentro y no fuera.

El ciudadano-habitante, siempre único y singular, imprevisible y del que solo cabe dar testimonio; así es como se explica en hecho, pero se comprende en acto, y resulta un ser unificado en cuanto a su memoria ${ }^{13}$, propósito actual e imaginaciones se halle estrechamente ligado y estará tanto menos expuesto al error en cuanto habite y pertenezca a una Ciudad que perciba y propicie abiertamente esa saludable 'construcción de conexiones constantes'.

Aquí podría estar la razón por lo que la Arquitectura y el Urbanismo en general, respiran con gran dificultad hoy en día. No tanto por los aprietos que el capital especulativo pone en su camino (que ya es bastante), sino porque arquitectos y urbanistas, abstraídos en la móvil continuidad de su jornada, a veces se niegan a aceptar la realidad de que todos nosotros respiramos el espacio desde dentro, e intuimos la forma construida de afuera: respiramos el espacio que las formas crean, y percibimos aquellos elementos que se pueden mover libremente, la vida urbana que se desarrolla al ras del suelo y de las paredes, mayor aún, experimentamos tenas y continuamente cambios, percibiendo la energía - desprendida por nuestras actividades y usos - como proyecciones del pensamiento sobre la materia; que no es más que el fiel reflejo de la "condición instable del territorio frente a nuestro deseo humano por permanecer"14 (Mejía y Mazo,2013).

Este aspecto de la realidad nos lleva a pensar que no debemos olvidar la temática residencial en los centros históricos, no sólo porque existe un vacío en las políticas y en el conocimiento generalizado, sino que aporta a la formulación de un nuevo paradigma en base a la construcción de lo cotidiano; más aún cuando ahora hemos entrado en

\footnotetext{
12. 'Usos' son todas aquellas conductas relativas al habitar. Representan la funcionalidad de un determinado fragmento de realidad para responder con justicia a las necesidades del usuario.

13. La memoria, en su forma más cabal, refleja la unidad y el orden racional de la vida en sociedad.

14. Para Mejía, S. y Mazo, E., las historias de los individuos están reguladas por el deseo, sujetos a impulsos intempestivos y casi incontrolables. Esa especie de refugios itinerantes que se construyen alrededor de los cuerpos y que tratan sobre "construcciones de lo cotidiano", son más delimitaciones de coreografías inesperadas. Mejía, S. y Mazo, E., (2013), La Metacalma, Madrid, España: CIRCO.
} 
crisis del pensamiento y se observa con fuerza la existencia de conceptos que obligan a la discusión crítica y no sólo la aceptación pasiva de sus construcciones teóricas.

En las últimas décadas, la vivienda en nuestra ciudad ha estado presente escasamente en algunos debates, sea para enseñar unas pocas casas excepcionales o ciertas "propuestas de vivienda pública que son permanentes déjà vu" (Herreros,2008:25); pero nada de eso tiene sentido hoy si queremos participar en los procesos que realmente definen el presente. Bajo esta premisa, nos interesaría poner más énfasis, en aquellos mecanismos capaces de negociar con situaciones y fenómenos de cambio no convencionales, a los que los ciudadanos debamos posicionarnos con la decisión de participar en ellos, para ir asumiendo que hay oportunidades fabulosas ocultas en esos fenómenos que consideramos 'de necesidad de vivienda en los centros históricos', y generar una renovación urbana que este estrechamente ligada a las nuevas sensibilidades que nos ocupan también como habitantes.

Si seguimos esta misma línea observaremos también el fin del monumentalismo ${ }^{15}$, esa curiosa devoción por la cáscara — de ahí la afición a las cajas, sobre todo a las cajas vacías- que cosifica y niega las relaciones que nos otorgan derechos como sujetos patrimoniales ${ }^{16}$; y que también la vivienda colectiva de cierta densidad dentro de nuestro Centro Histórico, asumiría un papel fundamental ya que es precisamente la condensación tridimensional lo que nos permitiría afrontar algunos desasosiegos urbanos, como la destrucción del suelo disponible, el crecimiento descontrolado de las ciudades y sobre todo la necesidad de asumir una cierta agenda sostenible a nivel municipal, etc.

Esta vivienda colectiva pública, abandonada actualmente en manos de burócratas y especuladores, si logra reinsertarse en la ciudad histórica, deberá afrontar además la demanda de formas de comunidad adaptadas al nuevo siglo: "asistimos actualmente a la superación de la satisfacción de una necesidad individual para sustituirla por el proyecto de la convivencia" (Herreros,2008:26), siendo este el factor primario de la vivienda colectiva a reivindicar y sustento fundamental de lo que llamamos cultura urbana contemporánea. Nuevas comunidades habitan nuestros centros históricos y la demanda de ingredientes cohesivos es una realidad de la que legos (aprendices) y expertos debemos ya hacer tema de trabajo.

Entonces "Vida contemporánea/ hogar histórico" (encabezado de nuestro manifiesto), consistirá en reconocer que, en este ir y venir, también hemos olvidado el momento en que renunciamos al verbo 'compartir' en los proyectos de vivienda colectiva, el momento en que desaparecieron las lavanderías comunitarias, el molino, el patio y el zaguán para celebrar el encuentro; el momento en que fomentar la coincidencia de las personas dejo de ser un objetivo, y con ello, todo un sistema cohesivo humano en el centro histórico de nuestra ciudad fue anulado.

Pero, el tiempo siempre hace su trabajo y el habitante homogéneo de los proyectos modelos del siglo pasado ha dado paso a una variedad de singularidades contemporáneas que están resultando incompatibles con la idea de universalidad de necesidades heredadas de la modernidad; identificando un anhelo comunitario creciente, justo hoy que entendemos que una nueva idea de 'encuentro' entre los ciudadanos-habitan-

15. Según la Real Academia Española 'monumentalismo', de monumental e -ismo: contempla dos significados: (1) $\mathrm{m}$. Tendencia a la utilización de grandes proporciones en las obras de arte, especialmente en las arquitectónicas o escultóricas. (2) m. Tendencia a fomentar la construcción de monumentos públicos como expresión de poder.

16. El 'sujeto patrimonial' hace referencia a una relación social que contiene tres componentes: un objeto (o qué se hereda), un momento (o cuándo se hereda) y los actores sociales específicos (o quién los hereda). Esta definición implica que lo patrimonial existe en la medida en que uno o varios sujetos lo reconocen, apropian y protegen como tal. 
devenir Vol. 7, Nº14, JULIO - DICIEMBRE 2020, PP. 53-70 - Estudios I ISSN 2312-7562 | E-ISSN 2616-4949

UNIVERSIDAD NACIONAL DE INGENIERIA, LIMA

doi: https://doi.org/10.21754/devenir.v7i14.758

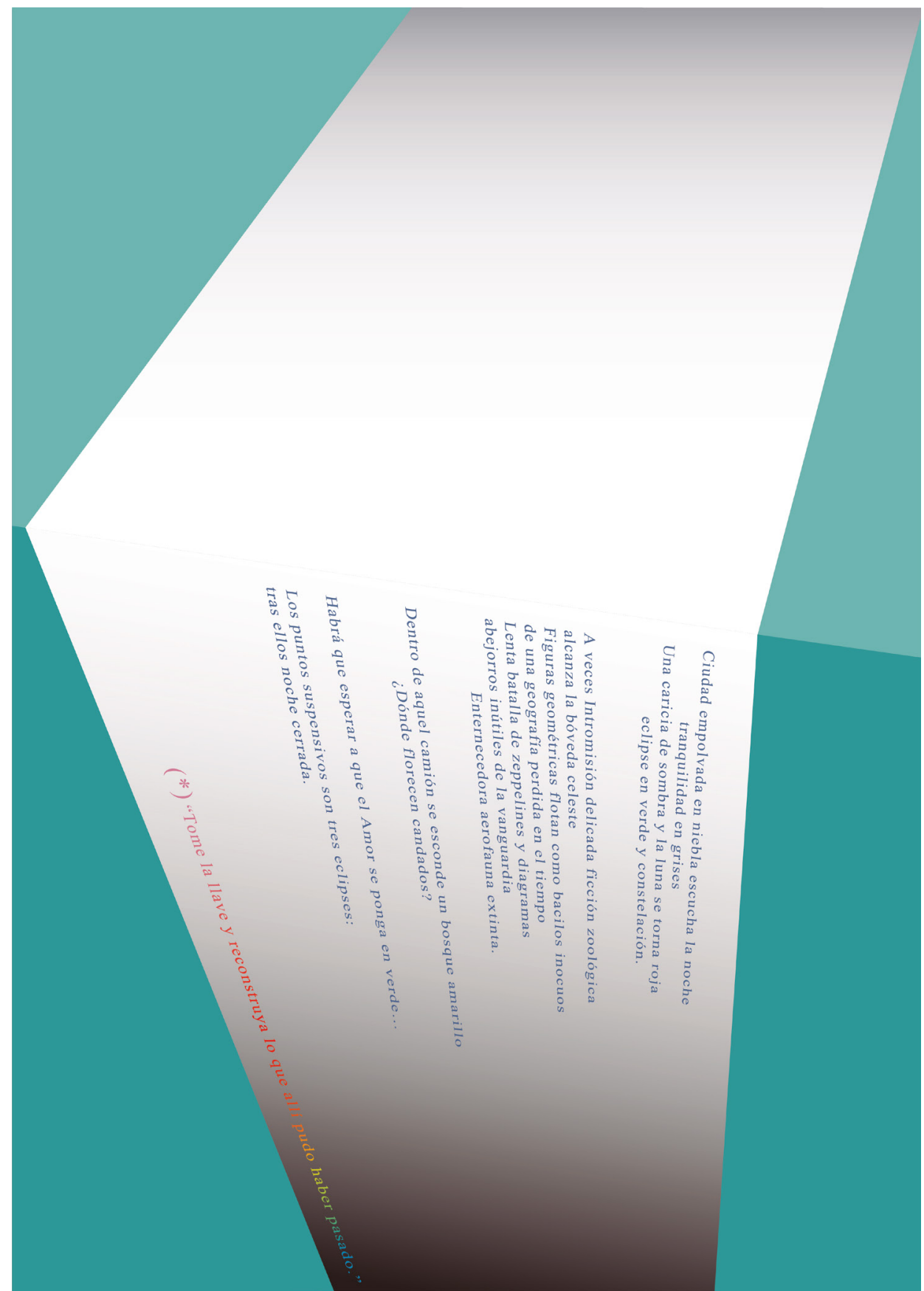

Figura 4. Imaginación en fábula vegetal. 120․ Poema visual. Elaboración propia, 2019.

tes tiene sentido basado precisamente en 'no tener mucho en común'. Podríamos describirlo como el deseo de compartir nuestra individualidad no para ser homologados, sino que queremos coincidir para beneficiarnos de la diversidad que el grupo ofrece.

Este deseo no siempre soporta mirar cara a cara a la realidad, lo sabemos, pero como una vez escuche: "cuando las cosas se ponen duras, la voluntad es determinante". Y eso es exactamente lo que empieza a sucedernos: apenas empezamos a nacer en tiempos difíciles $-\mathrm{y}$ en realidad la historia de la humanidad nunca los ha conocido fáciles- 
más nuestros padres, madres, abuelas y tatarabuelos no han dejado nunca de confiar en la existencia del bien, aumentando el peso de la tierra para hacer grávidos otros centros ajenos, que existen hoy en nosotros.

Ahora haremos una pausa, y si me permiten, a través de mis párpados entrecerrados, veré cómo mis ideas inclinan sus cabezas y desfilan en silencio fuera de la habitación. Cuando la última haya salido cerrando la puerta, saltaré de mi silla y comenzaré a pensar en una nueva. Finalmente, cuando decidimos pensar en nosotros mismos (y eso lo sabemos todos), no lo hacemos sobre la situación política, ni tampoco sobre la situación actual del país. Deseamos pensar sobre la condición humana tal y como la estamos experimentando en este mismo momento y la idea de 'casa' nunca fue, ni es un bien inmobiliario intangible, sino más bien la percibimos como un 'espacio de expectativa' que no sufre pasivamente en el tiempo, que se usa y expresa una vocación múltiple y compleja según las manifestaciones de quien lo habite.

Afortunadamente, lo que acabamos de advertir, implica una verdadera conexión y llamado a la acción, por consiguiente, asignamos voz a estas letras y decimos:

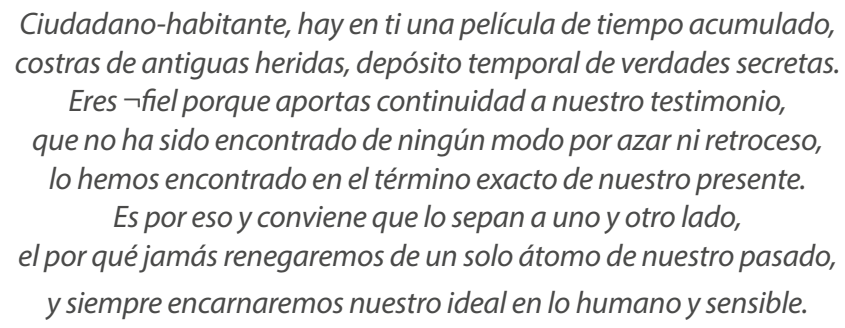

No olvidemos que este trabajo tiene su origen más alto en el esfuerzo, que es la verdad de nuestras construcciones y el valor de nuestras realizaciones como Ciudad.

Ánimo. (ver Figura 4).

\title{
Imaginación en fábula vegetal
}

\author{
(...) lo que no tuvimos que descifrar y esclarecer mediante nuestro esfuerzo personal, \\ lo que antes de nosotros estaba claro, no es propiedad nuestra. \\ Sólo procede de nosotros mismos lo que extraemos \\ de la oscuridad que hay en nosotros y no conocen los demás. \\ Marcel Proust \\ (de la película “Le Temps Retrouvée")
}

Lejos queda la necesidad de encontrar un único camino, de saber con precisión cual es el objetivo al que, inexorablemente, debemos encaminarnos. Hacer Ciudad, participar como aficionados dentro de este disparatado y competitivo mundo, acoge y hasta suscita intuir que la substancia de esta se acerca a la naturaleza de nosotros mismos, donde 'somos y estamos en cuanto tomamos conciencia de la orquestación universal en que se inserta nuestro papel individual'; por consiguiente a tal pensamiento, parecería significativo afirmar que el origen de la vida en Ciudad es una suerte de tensión entre lo humanamente individual y lo universalmente colectivo.

Los ciudadanos actuamos entre estas dos tendencias complementarias: una individual que se dirige a la concentración y dominio de nosotros mismos y otra colectiva que encamina la expansión y entrega de sí mismos hacia el medio ambiente del que somos parte. No hay duda, pertenecerse, darse, viene a ser el ritmo de la vida personal sin dejar de ser social, y ser conscientes de esta naturaleza dual, es lo que nos sitúa con respecto al mundo y con respecto a los otros en el presente fluido. 
devenir Vol. 7, N¹4, JULIO - DICIEMBRE 2020, PP. 53-70 - EstudIOS I ISSN 2312-7562 | E-ISSN 2616-4949

UNIVERSIDAD NACIONAL DE INGEEIERÍA, LIMA

doi: https://doi.org/10.21754/devenir.v7i14.758

Pero, ya que nuestra respuesta no está aislada, las ciencias biológicas también nos empiezan a contar el encuentro de comunidades errantes, bosques solares enteros, procesos respiratorios oceánicos, en fin lugares de encuentro, que no forman una mera yuxtaposición de partes, sino una verdadera conexión en la que cada cual ocupa su lugar y desempeña una función; accionados por esa ola continua de lo diverso y colectivo, que pasa a través de aquellos puntos en el espacio, estableciendo combinaciones nuevas de pensamiento y que, en otro paralelo, representan la misma combinación de todos nuestros casos posibles.

En suma, todo este enfoque nos lleva a reafirmar con gusto la idea que nuestra Ciudad nació desde el espacio público en profunda tensión entre individuo y colectividad. Y desde allí se organizó. La Plaza Mayor ${ }^{17}$ se llenó de ciudad —como ocurrió con las demás plazas y calles - para después desplegarse por todo el territorio. Esta Ciudad en su origen también contó con otras micro unidades urbanas en su seno, como los Tambos $^{18}$, casas de oficios y viviendas colectivas ubicadas en los bordes e ingresos de la plaza y vigentes hasta hoy a partir de las dos funciones clave de la época, primero como soporte para las actividades fundamentales de la vida en comunidad y segundo para reforzar su natural modo de habitarlo.

No obstante, conociendo el peso que tuvo el espacio público, la vivienda y sus habitantes para la construcción de Ciudad, las tendencias conservacionistas miraron parcialmente esa realidad y su omisión se sustentó principalmente en atributos y no en relaciones; por eso, sobre la base de la visión 'monumentalista' negó que todas las ciudades son históricas, que todos los componentes de una ciudad incluyendo la vivienda son históricos y, por lo tanto, que todos sus habitantes también son históricos. Tal vez, pese a su destino idílico, sea más digna la actitud existencial que valide hoy un cambio de concepción y permita plantear políticas integrales ${ }^{19}$, por primera vez, desde el ciudadano-habitante del Centro Histórico y desde una institucionalidad de gobierno que otorgue sentido a la renovación urbana ${ }^{20}$ como nuevo orden.

Ahí estaría la verdadera definición de 'rehabilitar', aunque la que usamos generalmente, no refleja la realidad de los hechos. El diccionario de la Real Academia Española define 'Rehabilitar' como "habilitar de nuevo o restituir a alguien o algo a su antiguo estado". La rehabilitación opera como una reparación dinámica, en la que reparar es parte de una continuidad, que se define como someter a una materia a un determinado proceso para volver a ser utilizable. Pero probablemente la realidad vaya otra vez conforme a la influencia que aún tienen las concepciones monumentalistas, que consagra tantos esfuerzos inútiles en realizar proyectos vinculados a la economía de los centros históricos, a partir del turismo y de éste priorizando a los monumentos más significativos. En otras palabras, se sigue construyendo una lógica circular que gira sobre lo mismo: todo sale y llega a lo monumental.

17. La 'Plaza Mayor' es la plaza principal de algunas localidades en el urbanismo castellano e hispanoamericano. Particularmente en algunos países de América, reciben el nombre de 'Plaza de Armas'. Como concepto urbanístico, es un espacio abierto que permite el contacto y la comunicación entre los ciudadanos y una gran cantidad de funciones urbanas.

18. Los Tambos de Arequipa son un conjunto de viviendas que datan de la época Colonial del Perú. Se emplazaron en el margen izquierdo del río Chili por lo que adquirieron primero un rol de alojamiento temporal y luego como vivienda que, a la par, servía como molinos, lavaderos de lana, corrales y talleres de manufacturas (talabarterías, sastrerías, herrerías, etc.).

19. Se requiere que las ciudades dispongan de una fuerte identidad sociocultural y de un liderazgo político autónomo y representativo. Sobre esta base deberán generar proyectos colectivos que proporcionen a la sociedad urbana la espontaneidad movilizadora de todos sus recursos potenciales.

20. La renovación implica la creación de un 'nuevo orden' que surge de la necesidad de construir una voluntad colectiva que respete los 'múltiples órdenes' y no la hegemonía de uno de ellos. Es una propuesta que tiene que ver con la relación entre antiguo y moderno, y con las vinculaciones que establecen los portadores de estos órdenes: los sujetos patrimoniales. 
Lo complicado de este escenario, es que encuentra una aceptación que sigue siendo inexplicable y muy por el contrario de oponerse — con una dosis de desvergüenza poco común pero en justa relación con la ingenuidad y el desconcierto del ciudadano- la Política Nacional de Vivienda ${ }^{21}$ tampoco ha entendido como tema básico la función residencial dentro de los centros históricos, porque en general las políticas de vivienda que ejecutan los gobiernos están referidas a vivienda nueva y localizada en las periferias. ¿Por qué? Porque se 'supone' —y no es así- que construir vivienda en la periferia es más barato, por el bajo precio relativo del suelo y porque el esquema de subsidio habitacional a la oferta beneficia a los grandes proyectos inmobiliarios y al capital especulativo, que son impulsados por los desarrolladores urbanos privados al margen de los intereses de toda una Ciudad que desea crecer saludablemente.

Felizmente, el pasado se suelda al futuro una y otra vez, y trabajar sobre la vivienda construida en nuestro Centro Histórico es, en definitiva, plantearse nuevos modos de vida en los que se aumente la densidad en favor del desarrollo: vivienda colectiva pública de cierta densidad, basada en la multifuncionalidad y la diversidad dentro de un marco normativo que proteja y respete el patrimonio ${ }^{22}$ existente. Significa equilibrar usos residenciales con la actividad económica acorde al entorno urbano que potencie sus elementos característicos y preserve no sólo una área patrimonial y cultural del Centro Histórico, sino también sus contenidos sociales y económicos para su sostenibilidad. Iniciativas que si bien necesitan de una gestión inicial de carácter administrativo su puesta en marcha y posterior desarrollo estará en manos de nosotros: los ciudadanos-habitantes de nuestra Ciudad. Punto y aparte.

Al parecer, las verdades que tan lejos queremos buscar, solo tienen valor si aceptamos la poderosa fragilidad de la 'imagen' de Ciudad contemporánea que tenemos, cuyo predominio en nosotros es la vida refleja sobre la espontánea. Bien pudiera evocar, con la complicidad de ustedes los lectores, el sucederse vertiginoso de algunas cuestiones críticas de nuestras vidas, demostrarnos cuanto los atributos de las cosas son fruto de nuestra mirada. Y no sólo porque hace presente, en la penumbra, todo aquello que no desearíamos que existiese, sino más bien por esa tupida trama de diversidad e ingenuidad, esa abultada intimidad que acompaña el sendero es, nada más que, un tenaz esfuerzo por materializar nuestros deseos y anhelos desbocados en esta época; y si en algunos instantes los acontecimientos expuestos aquí parecen contrariarles - junto con un rostro contrariado- no encuentro razón que les impida preferir una idea de otra. Sin embargo, no existe en estas líneas ninguna falsedad y todo es parte de la posibilidad intuitiva que mi opinión sugiere.

Nada pues, tan ambiguo como el clásico problema de las relaciones entre personas: individuo vs. comunidad - como si la individualidad fuera interior a la persona y la comunidad exterior - postularemos, no un acto de razón individual, ni de alma colectiva, si no en un ejercicio de consciencia (y quizás de consciencia bastante saludable), declaramos que el drama que vivimos como ciudadanos contemporáneos es, si cabe decirlo, un drama histórico : bien, participamos individualmente de nuestra propia historia, o participamos colectivamente en la historia del mundo. No. Es ambas incesante y recíprocamente trabajadas.

21. El Ministerio de Vivienda, Construcción y Saneamiento (MVCS) ha diseñado la Política Nacional de Vivienda y Urbanismo (PNVU). Esta responde a la necesidad de enrumbar al Perú hacia el desarrollo sostenible habitacional en un nuevo contexto caracterizado por fenómenos globales, un nuevo orden económico y político, y la creciente tendencia hacia la urbanización del territorio.

22. Desde esta perspectiva, el'patrimonio' encuentra sentido en su democratización y no en la exclusión, en el procesamiento del conflicto y no en el ejercicio de la violencia. En otras palabras, la preservación de los valores del patrimonio depende de su deselitización, apropiación social, promoción como interés general y del fortalecimiento del sentido de ciudadanía, entre otros. 
devenir Vol. 7, N¹4, JULIO - DICIEMBRE 2020, PP. 53-70 - EstudIOS I ISSN 2312-7562 | E-ISSN 2616-4949

UNIVERSIDAD NACIONAL DE INGEEIERÍA, LIMA

doi: https://doi.org/10.21754/devenir.v7i14.758

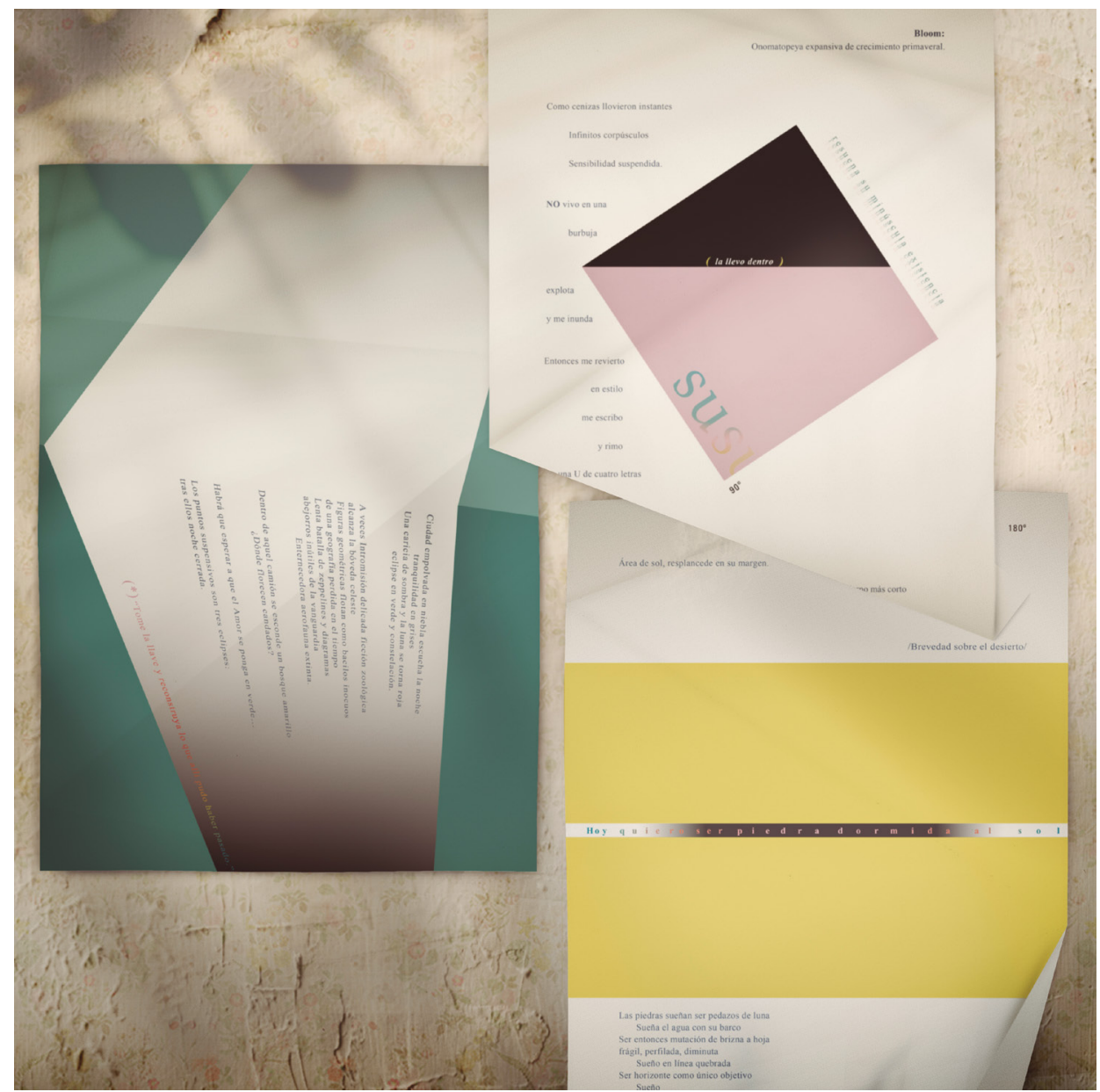

Figura 5. Serie de poemas visuales del manifiesto "Ciudad histórica habitada". Formas experimentales de lenguaje verbal y no verbal que evocan diversas percepciones según la mirada el lector. Elaboración propia, 2019.

Creemos, que el ciudadano realiza su complejidad existencial según cierto modo que llamaremos 'doble frenesí, gracias a una pareja de contrarios: lo individual y lo comunitario, a la vez antitéticos y complementarios, digamos correlativos, que hacen sentir su constante presencia, pero que, por su misma oposición, lo mantienen siempre en tensión y le impiden perderse en cualquiera de ellos. En realidad, nosotros, los ciudadanos-habitantes, estamos siempre entre lo individual y lo social, ambos nos son interiores, pues son categorías nuestras; y toda revolución auténtica — la ciudad que soñamos: la utopía múltiple cosida a la realidad - ha de ser indisolublemente individualista y comunitaria a la vez, y solo fracasará en la medida en que se sacrifique uno de los términos por el otro.

Poniendo limites, por lo extenso del tema y por no caer en una crítica generalizada, empezamos ya a notar la falta de tensión de ese 'doble frenesí' en la pérdida de identidad social de nuestra Ciudad, oculta detrás de una - no falsa, pero si incompleta - revitalización de nuestros espacios heredados; teniendo como resultado la poca presencia de vivienda colectiva e identitaria en el Centro Histórico, la generación de espacios de exclusión social y fundamentalmente la ausencia de lugares de desarrollo individual y comunitario, que se convierten, hoy en día, en las deudas que a nosotros como cocreadores de nuestras sociedades y territorios se nos plantean. 

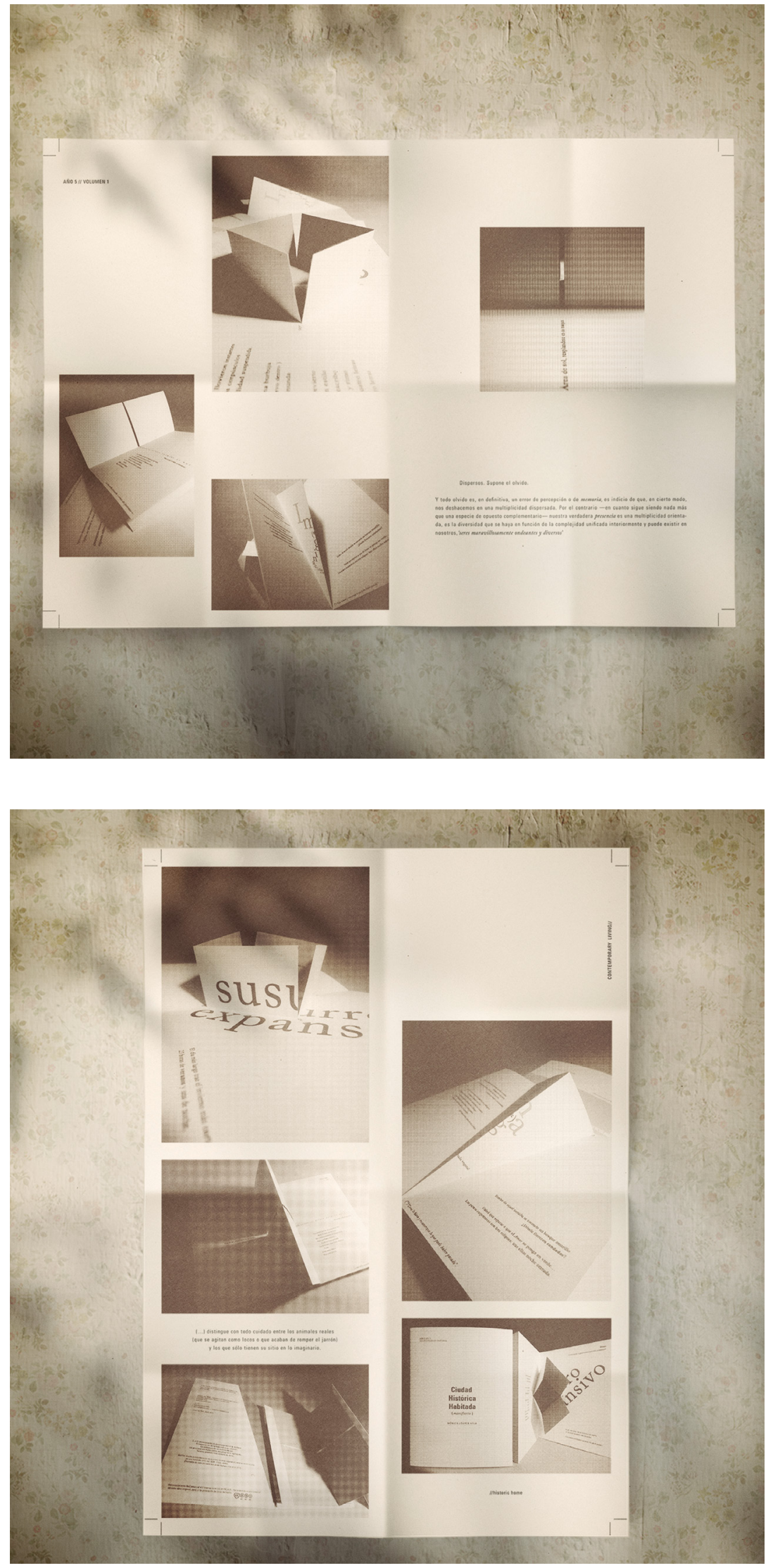

Figura 6. Versión'pop-up' del manifiesto "Ciudad histórica habitada". Composición fotográfica $\mathrm{N}^{\circ} 1$. Propuesta complementaria de construcción sencilla y portable, utilizando la técnica de plegado 'pop-up'. Elaboración propia, 2019.

Figura 7.Versión'pop-up' del manifiesto "Ciudad histórica habitada". Composición fotográfica №2. Elaboración propia, 2019. 


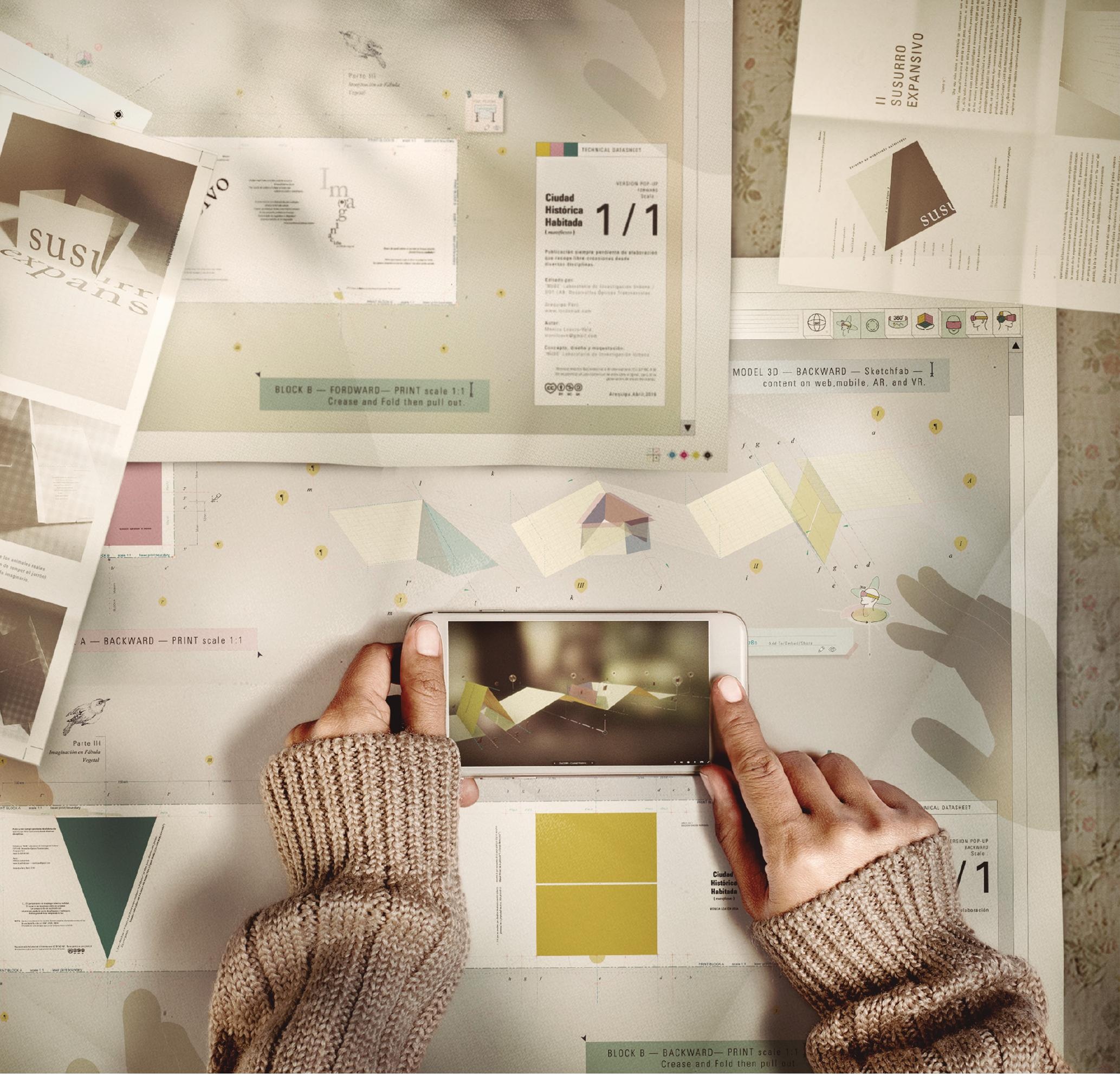

Figura 8. Múltiples formatos de lectura del manifiesto "Ciudad histórica habitada". Propuesta complementaria de impresión y lectura. Elaboración propia, 2019.
En fin, nuestra Ciudad Histórica Habitada ${ }^{23}$ florecerá tan pronto como los suaves ajustes de la reciprocidad empiecen a trabajar en este clima de relatividad, en el campo de todos los fenómenos posibles, la materia se presentará como lo que es: vitalizable; la vida como lo que presiento es: una preparación, crecer a cielo abierto. Entonces, y más próximos al principio, será gracias a esta relación dentro y fuera de nuestras creaciones que podremos entender quiénes somos y testimoniar que pertenecemos al mundo y nos debemos el aire que todos respiramos (ver Figuras 5, 6, 7, 8, 9 y 10).

23. Según conceptualiza Loayza y Subia (2018) en el libro La Cabezona Tambo de la Memoria, la 'Ciudad Histórica Habitada' es el conjunto urbano o pueblo tradicional, asentando sobre las formas de existencia actual de zonas urbanas históricas. Sus habitantes mantienen viva la memoria heredada por sus antepasados a través de relaciones respetuosas y democráticas con el entorno que la circunda. 


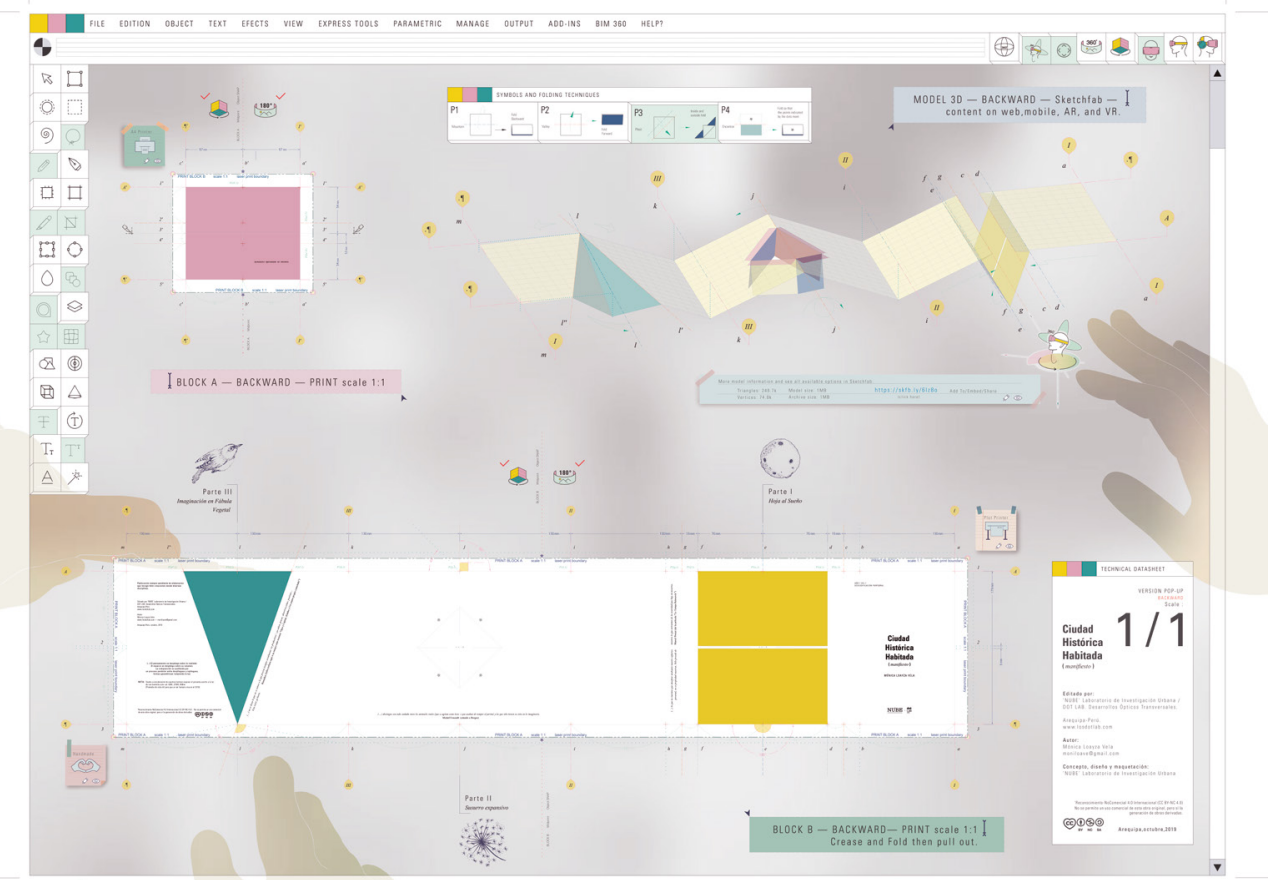

Figura 9. Versión 'pop-up' del manifiesto “Ciudad histórica habitada”. Plano de impresión, corte y plegado. Cara anverso. Escala 1/1. Elaboración propia sobre la base de http://bit.ly/CHH_pop-up_DEVENIR (free donwnload), 2019.

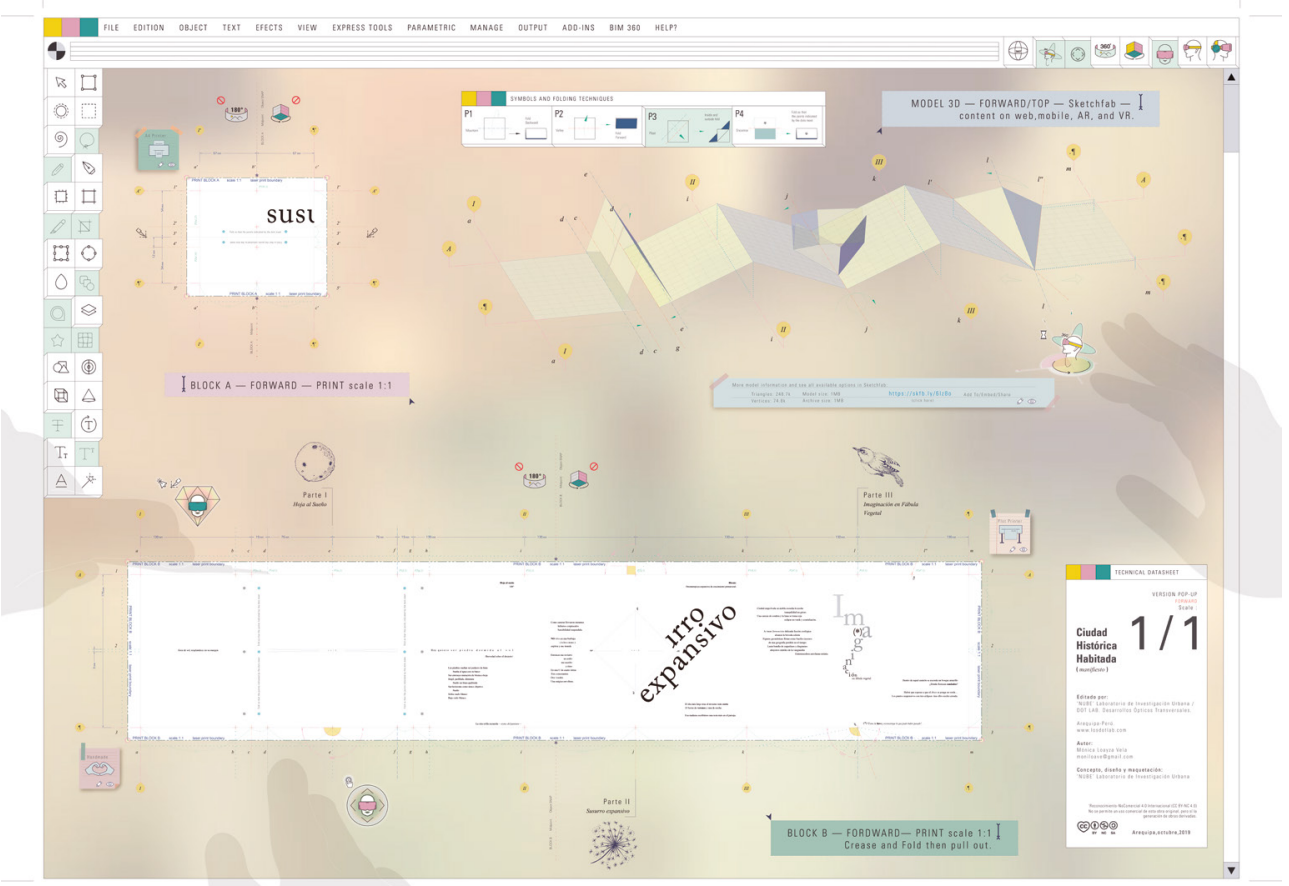

Figura 10. Versión ‘pop-up’ del manifiesto “Ciudad histórica habitada”. Plano de impresión, corte y plegado. Cara reversa. Escala 1/1. Elaboración propia sobre la base de http://bit.ly/CHH_pop-up_DEVENIR (free donwnload), 2019. 
devenir Vol. 7, N¹4, JULIO - DICIEMBRE 2020, PP. 53-70 - EstudIOS I ISSN 2312-7562 | E-ISSN 2616-4949

UNIVERSIDAD NACIONAL DE INGGENIERÍA, LIMA

doi: https://doi.org/10.21754/devenir.v7i14.758

\section{Referencias}

Alexander, C. (1981). El modo intemporal de construir, Barcelona, España: Editorial Gustavo Gili.

Beck, U. (1998). ¿Qué es la globalización?, Barcelona, España: Editorial Paidós.

Boldrini, P. y Malizia, M. (2014). Procesos de gentrificación y contra gentrificación. Los mercados de abasto y del norte en el gran San Miguel de Tucumán (noroeste argentino). En INVI revista del Instituto de Vivienda del Distrito Federal de México, 29(8), 157-191.

Borja, J. (1988). Democracia local: Descentralización del Estado, Políticas económico-sociales en la

ciudad y Participación popular, Documents d'Autonomia Municipal, (1), Barcelona, España: Ajuntament de Barcelona.

Cabrera, V. (1997). Políticas de renovación en centros históricos. Revista SIAP XXIX, Cuenca, Ecuador: SIAP.

Eirinherg, K. (1997). Las multinacionales ven un sentido de utilidad escalar y de relaciones públicas en la conservación cultural. La Era urbana, (4). Quito, Ecuador: Editorial Imprimax. Ma.

Foucault, M. (1968). Las palabras y las cosas. Buenos Aires, Argentina: Editorial Siglo XXI.

González, H. (2002). Caminos hacia lo alternativo dentro del ámbito conceptual, proyectual y contextual de la arquitectura. Tesis doctoral. Barcelona, España: Escuela Técnica Superior de Arquitectura de Barcelona.

Hardoy, J. y Dos Santos, M. (1984). Centro histórico de Quito, preservación y desarrollo. Quito, Ecuador: PNUD / UNESCO.

Herreros, J. y Rodríguez, M. (2008). Vivienda y espacio doméstico en el siglo XXI, Madrid, España: La Casa Encendida.

Montaner, J. y Muxí, Z. (2011). Arquitectura y política. Ensayos para mundos alternativos. Barcelona, España: Gustavo Gili.

Municipalidad Provincial de Arequipa. (2010). Tambos del Barrio del Solar. Arequipa, Perú: Oficina Técnica del Centro Histórico Arequipa.

Lacroix, J. (1964). El sentido del diálogo. Barcelona, España: Editorial Fontanella.

Loayza, M. (2014). Centro de Interacción Social y Producción Cultural Colaborativa para la juventud en cerro Colorado-Arequipa. Tesis para optar el Título Profesional en Arquitectura y Urbanismo. Arequipa, Perú: Universidad Nacional de San Agustín.

Loayza, M. (2015). OuCh;\#1 Laboratorio de Musas: http://losdotlab.com/arte/ouch1-laboratorio-de-musas/

Loayza, M. y Subia, C. (2018). La Cabezona Tambo de la Memoria. El patrimonio como memoria social: Representación del pasado e identidad cultural en la ciudad histórica habitada de Arequipa. Lima, Perú: Asociación Cultural Apoyomutuo.

Mejía, S. y Mazo, E. (2013). La Metacalma. Madrid, España: CIRCO M.R.T.

Sabatini, F., Sarella, M. y Vásquez, H. (2009). Gentrificación sin expulsión, o la ciudad latinoamericana en una encrucijada histórica. Revista 180, (24), 18-25. 